\title{
Electroless Plating of Palladium Membranes on Porous Substrates for Hydrogen Separation and the Effects of Process Factors on Plating Rate and Efficiency: A Review
}

\author{
Abubakar Alkali ${ }^{1,2}$ \\ ${ }^{1}$ Centre for Process Integration \& Membrane Technology, School of Engineering, Robert Gordon University, \\ Aberdeen, UK \\ ${ }^{2}$ Department of Petroleum and Natural Gas Engineering, Baze University, Abuja, Nigeria \\ Email: abubakar.alkali@bazeuniversity.edu.ng
}

How to cite this paper: Alkali, A. (2020) Electroless Plating of Palladium Membranes on Porous Substrates for Hydrogen Separation and the Effects of Process Factors on Plating Rate and Efficiency: A Review. Journal of Power and Energy Engineering, 8, 1-19.

https://doi.org/10.4236/ipee.2020.82001

Received: September 30, 2019

Accepted: February 15, 2020

Published: February 18, 2020

Copyright $\odot 2020$ by author(s) and Scientific Research Publishing Inc. This work is licensed under the Creative Commons Attribution International License (CC BY 4.0).

http://creativecommons.org/licenses/by/4.0/ (c) (i) Open Access

\begin{abstract}
The electroless plating of palladium and palladium alloy membranes is fast becoming an important and enabling technology. This is more so when juxtaposed with the rising demand for high purity hydrogen for applications particularly in proton exchange membrane fuel cells (PEMFC). The effect of process factors such as sensitization and activation during surface modification, concentration of the reducing agent, plating temperature, time, $\mathrm{pH}$, additives, air aeration on plating efficiency, quality of the palladium film and deposit morphology is reviewed with the aim of identifying areas requiring further investigation. The paper also reviews how these process factors could be optimised for better plating efficiency and overall membrane quality. The concentration of the reducing agent has been identified as the limiting factor on plating efficiency albeit other process factors separately impact on the plating efficiency. Furthermore, bulk precipitation caused by concentration of the reducing agent has been identified as a major problem during electroless plating with hydrazine based plating baths. To ameliorate this problem, a multi step addition of the hydrazine reducer in separate portions has been recommended.
\end{abstract}

\section{Keywords}

Electroless Plating, Hydrogen, Palladium Membranes, Plating Efficiency, Process Factors

\section{Introduction}

The Electroless plating method for the deposition of dense films over porous 
substrates has recently assumed increasing importance and wider applications in the fabrication of composite $\mathrm{Pd}$ and $\mathrm{Pd}$-alloy membranes for hydrogen production, separation and purification [1]. Some of the several advantages the electroless plating method has over other methods include its uniformity and easiness of coating over any surface of any shape, no energy supplies required, low cost, simple equipment as shown in Figure 1 and it also avoids accumulation of the deposits around the substrate edges to ensure in uniformity of coating [1]. However, it also has its drawbacks such as its time consuming procedure as a result of the several treatment steps involved [2].

Hydrogen production and purification using the novel membrane reactor module is gaining considerable attention due to the process intensification concept potential of the membrane reactor to integrate hydrogen separation and reaction in a single unit [3]. This unique ability of the membrane reactor enables an improved performance to be achieved such as an increase in reactant conversion and product selectivity through the removal of one of the products in a dehydrogenation reaction or to perform a hydrogenation reaction by dousing hydrogen through the membrane [3] [4]. This concept can be used in steam methane reforming and other hydrocarbon reactions and it offers several benefits in terms of increasing product conversions and cost reduction [5]. Palladium membranes have infinite selectivity for hydrogen due to their ability to transport hydrogen which is as a result of the very high solubility of hydrogen in the bulk over very wide temperature ranges [2]. In palladium based membrane reactors, palladium membranes can be used in an equilibrium limited reaction to remove one of these products and increase the conversion or to selectively saturate hydrogen through the membrane although in both scenarios, palladium has a catalytic function [4]. Ultra pure hydrogen is in demand and widely used in petroleum and petrochemical industries such as in petroleum refining, production of ammonia and methanol [6] [7]. However, more recently, advances in polymer electrolyte membrane fuel cell (PEMFC) for both stationary and vehicular applications has led to a surge in demand for ultra pure hydrogen [8].

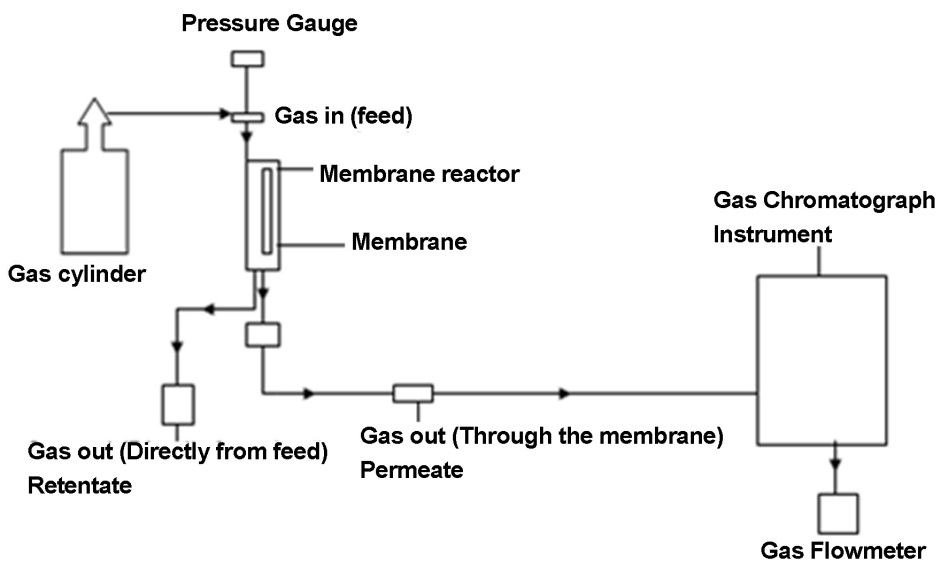

Figure 1. Concept schematic of permeation set up for hydrogen and related processes using membranes. 
Palladium membranes are the membranes of choice for hydrogen because they permeate only hydrogen when dense [5]. In decades past, thick palladium films in standalone forms were used with a thickness ranging from $10 \mu \mathrm{m}-200$ $\mu \mathrm{m}$ and low hydrogen permeance, high cost and lacking the mechanical and thermal strength to withstand harsh operating conditions such as high temperature [2].

As a result of the challenges caused by the standalone thin palladium films, the focus has now shifted to composites where a thin palladium layer is deposited on porous support. These composites have several advantages over thin films including high hydrogen permeance as a result of the very low resistance to hydrogen permeation, high mechanical strength and low cost [2]. Thin palladium films with different thickness are produced using various methods of membrane fabrication such as chemical vapor deposition, electroplating, magnetron sputtering and electrochemical deposition. However, electroless plating is widely regarded as the most efficient and convenient method for preparation of composite palladium membranes because of its uniformity of coating [2]. The mechanism of electroless plating for the fabrication of palladium-based composite membranes has been well investigated and the experience is that the method has a near perfect throwing power due to its applicability in both conducting and nonconducting surfaces and is applicable as long as the plating solution has access to the substrate surface [1]. The method enjoys an ever-growing popularity due to the several advantages it enjoys over other methods including uniform coating, low cost, strong adhesion of the metallic layer on the substrate, simple equipment and procedure [9]. Electroless plating also avoids a build-up of the solution on the substrate edges thus resulting in a uniform and dense coating [1]. In the preparation of composite membranes using the electroless plating method, a porous support such as stainless steel, Vycor glass and alumina is required onto which a dense metallic film is deposited [2]. Ceramic alumina supports are usually preferred due to their stability at high temperature and pressure and also their uniform pore distribution which enhances the fabrication of defect-free membranes [2]. The quality of deposits and cost implications of the electroless plating process depends on several process factors which include operating temperature, plating time, plating area, concentration of reducing agents, $\mathrm{pH}$, stabilising agents, and additives [10] [11]. The broader applicability and overall efficiency of the electroless plating method depends on the optimisation of these factors to improve both the uniformity of coating and quality of the metallic film deposits [11]. In the conventional electroless plating process, the major problem is how to achieve uniform densification of the palladium layer and also prevent mass transfer from the film into the solution. However, optimisation of these process factors is one critical way of ameliorating the mass transfer problem in the conventional electroless plating [8] [9].

This overview critically discuss the effects of the process factors on plating rate and efficiency of the electroless plating of Palladium-based membranes on 
porous support and the areas requiring further investigation. The scope of this paper is relevant especially considering the growing significance of membrane technology in hydrogen processes including its production, separation and purification for PEM fuel cell systems and also in several processes such as chemical synthesis, hydrogenation, semiconductor and manufacturing in the petroleum and petrochemical industry [12] [13].

The need for a better understanding and optimisation of the electroless plating method is more so when juxtaposed with the critical challenge of how to prepare thin, dense, uniformly coated and defect free Pd-based composite membranes that are selective to hydrogen and have long term durability [14]. To my knowledge, so far there has not been a review of the effect of these process factors on the efficiency of the electroless plating process.

The steps in electroless plating depend on the type of support but generally involve cleaning of the substrate, surface modification (which is usually a 2 step process of sensitization and activation), deposition of the palladium layer, drying and annealing of the membrane to activate the palladium layer [10]. The cleaning step is meant to remove any organic contaminants and to chemically prepare the substrate for the sensitization and activation steps and involves washing the substrate in an ultrasonic bath at temperatures $60^{\circ} \mathrm{C}-70^{\circ} \mathrm{C}$ with distilled water and ethanol/isopopanol followed by drying at temperatures between $120^{\circ} \mathrm{C}$ $130^{\circ} \mathrm{C}[7][10]$.

\section{Sensitization and Activation}

Prior to the deposition of the metal on the support, the sensitization and activation steps are carried out on the porous ceramic substrate so as to create catalytic sites on the non-metallic surfaces and to also stimulate the adsorption of the metal ions, enhance strong adhesion of the Pd nuclei on the substrate and eliminate induction period of the metal to ensure better uniformity of coating and improved membrane quality [9] [15]. A picture of the Alumina ceramic support is shown in Figure 2.

Several sensitization solutions have been used such as $\mathrm{SnCl}_{2}, \mathrm{AgNO}_{3}$, metallic $\mathrm{Na}$ in Naphthalene solution and $\mathrm{AuCl}_{3}$. However, the most commonly used is $\mathrm{SnCl}_{2}$ while $\mathrm{PdCl}_{2}$ is typically used as the activation solution to deposit Nanosized Pd nuclei on the porous substrate [15] [16]. Although surface activation is a standard requirement in electroless plating, it has its downside such as its time consuming nature, tin impurities, metal loss, and difficulty in control of film thickness and involves several steps which make it prone and susceptible to errors [7] [16].

Palladium can coexist with Tin during the sensitization step and this could affect the activity of Palladium towards hydrazine reducer thus slowing the rate of reaction and leading to a decrease in the deposition rate of the Pd metal [1] [7]. On the upside, it creates catalytic sites and also reduces the time it takes for the commencement of the deposition of palladium seeds onto the porous support which is also known as the induction period [15]. The pre-treatment steps to 


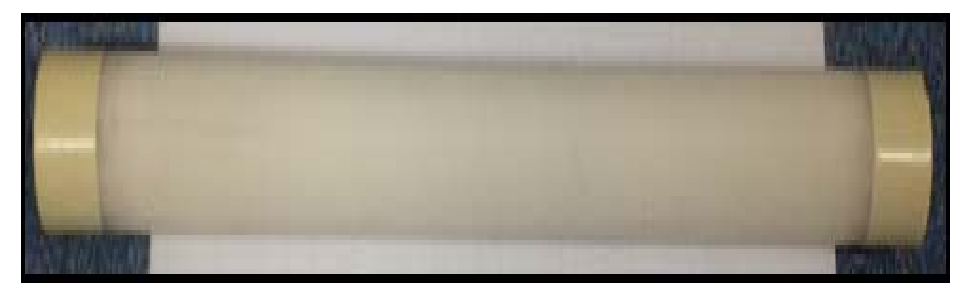

Figure 2. An unmodified commercial alumina membrane support.

deposit Pd nuclei onto the substrate also reduce the induction period and improves the plating efficiency [15]. The several steps and components of the electroless plating set up are shown in Figure 3.

K. L. Yeung and coworkers (1999) [15] compared the deposition rate of a clean support with the rate in a sensitized and activated support and reported a reduction in the induction period of up to 20 minutes for the palladium activated support.

Similar findings were reported by T. N. Khoperia (2003) [17] who investigated the effect of sensitization in electroless plating of Ni-P alloy and reported a decrease in the induction period and uniform coating after sensitization which underscores the relevance of sensitization during surface modification in electroless plating. Without activation, the induction time for 1 hour plating could be as much as between $20-45$ minutes [15]. A longer induction time could affect the plating rate and lead to low plating efficiency and uneven coating which amplifies the need to identify a plating bath composition that could lead to minimal induction period in order to achieve high plating efficiency and improved quality of the Palladium film [15] [17].

The sensitization and activation cycle has been reported to be typically as follows [15] [16]:

1) Substrate dipped for 2 minutes in the solution and rinsed for 30 seconds in distilled water.

2) Substrate dipped in the activation solution for 2 minutes and rinsed for 30 seconds in distilled water.

The above procedure is repeated 10 times to obtain an evenly seeded support [7] [16]. Several authors reported a cycle of 10 dips in both solutions at a dipping time of 5 minutes each for the sensitization and activation solutions followed by rinsing in distilled water for about 25 seconds [7] [16].

The electroless plating process is also time consuming and the time between dips also adds to the cumbersome nature of the electroless process and makes it prone to errors and impurities [7]. To solve these problems, Li Anwu and coworkers (1996) [7] used a modified method where the sensitization step was skipped which avoided the tin impurities, improved the rate of palladium deposition and the metal adhesion to the porous support. In their work, this group of workers modified the $\gamma$-AlOOH sol with $\mathrm{PdCl}_{2}$ solution and deposited same on the porous Alumina support which ensured that the Pd seeds will be deposited on the surface of the substrate directly without having to carry out the prolonged 


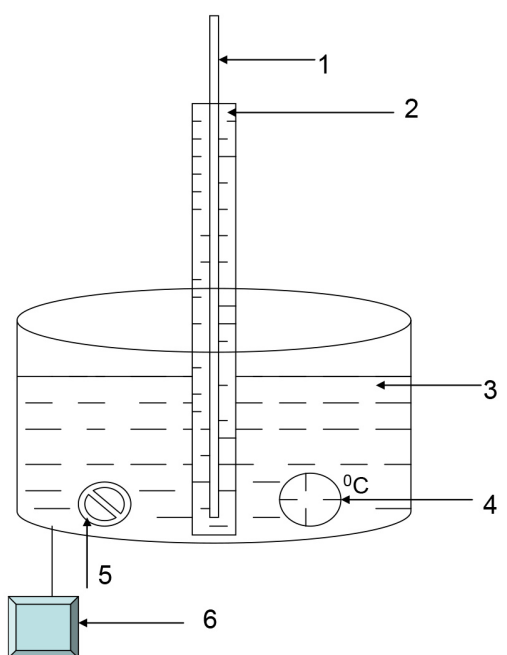

(a)

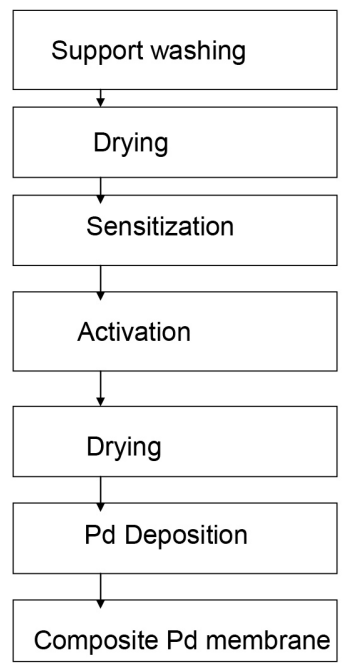

(b)

Figure 3. Electroless plating experimental set up (a) and preparation steps (b): (1) Alumina support; (2) Plating solution; (3) Water Jacket; (4) Temperature Control; (5) Power Switch; (6) Power Source [9].

activation process [7]. Furthermore, the skipping of the sensitization step ensured that no Sn (11) solution was used and hence no tin impurities are likely to be formed [7].

In a similar trend, Zhao and his group (1998) [18] reported another modified method where the $\gamma$-alumina support was activated by a palladium-modified AlOOH sol. This method produced a smooth surface free of pinholes and defects and effectively avoided the impurities associated with the sensitization step. However, it involved complex and lengthy procedures such as drying the gel-coatings for 48 hours, calcination at $600^{\circ} \mathrm{C}$ and reduction of the substrate in hydrogen at $500^{\circ}$ [18]. Modifying the support with a palladium modified $\mathrm{AlOOH}$ sol will ensure there are enough Palladium nuclei to create catalytic sites on the porous support [19].

Li Na XU et al. (2002) [20] also developed a modified method for electroless plating without the $\mathrm{SnCl}_{2}$ sensitization which effectively avoided the $\mathrm{Sn}$ (11) impurities. In their work $\mathrm{Li} \mathrm{Na} \mathrm{Xu}$ and his group activated the surface of silicon wafers with palladium nuclei by forming a covalently bonded self assembled monolayers (SAMs) of aminopropyltriethoxysilane (APTS) on the silicon surface and then activated the substrate with $\mathrm{PdCl}_{2}$ solution. Apart from skipping the sensitization step, this method also enhanced the adhesion of the deposited metal and also avoided the usual surface roughening problems [20]. Figure 4 shows the SEM images of the outer, inner and cross sectional area taken after sensitization and activation of the $\mathrm{Al}_{2} \mathrm{O}_{3}$ support in Alkali and Gobina's work on Electroless plating of palladium on $\mathrm{Al}_{2} \mathrm{O}_{3}$ ceramic support. Figure 4 (c) shows flowery pores and a uniform growth of the Pd nuclei which enhances the formation of the Pd layer after the plating process with strong adhesion to the substrate [15]. 


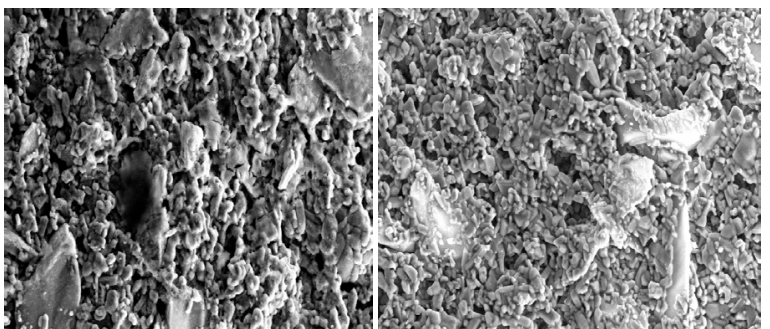

(a) (b)

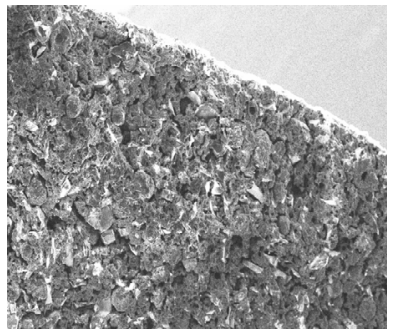

(c)

Figure 4. SEM Images of $\mathrm{Al}_{2} \mathrm{O}_{3}$ support after sensitization: (a) Outer section (b) Inner section (c) Cross-sectional area.

\section{Review of Electroless Plating Process Factors}

\subsection{Reducing Agent}

The common reducing agents used for the electroless plating of palladium and palladium alloy membranes are hydrazine, hydrophosphite, borohydride, dimethylamine boron and formaldehyde [21]. However, hydrazine and hyphoposphite are the more commonly used while formaldehyde is more commonly used in electroless copper plating [21] [22]. Although, hydrazine results in a better plating efficiency and was the first reducing agent to be used in the first electroless plating bath developed by Rhoda in 1958 but being a class- 11 carcinogen, it has its obvious drawbacks which makes hyphoposphite also highly considered [22]. Apart from the advantage of not being susceptible to bulk precipitation, hypophosphite also has the advantage of maintaining a constant plating rate for a longer plating time and this is necessary for uniformity of coating and high quality Palladium deposits [22].

In the electroless plating of palladium in a hydrazine based bath, the redox reaction can be represented as follows [15]:

$$
\begin{gathered}
2 \mathrm{Pd}\left(\mathrm{NH}_{3}\right)_{4}^{2+}+4 \mathrm{e}^{-} \rightarrow 2 \mathrm{Pd}^{0}+8 \mathrm{NH}_{3} \quad \mathrm{E}^{0}=0.0 \mathrm{~V} \\
\mathrm{~N}_{2} \mathrm{H}_{4}+4 \mathrm{OH}^{-} \rightarrow \mathrm{N}_{2}+4 \mathrm{H}_{2} \mathrm{O}+4 \mathrm{e}^{-} \quad \mathrm{E}^{0}=1.12 \mathrm{~V} \\
2 \mathrm{Pd}\left(\mathrm{NH}_{3}\right)_{4}^{2+}+\mathrm{N}_{2} \mathrm{H}_{4}+4 \mathrm{OH}^{-} \rightarrow 2 \mathrm{Pd}^{0}+8 \mathrm{NH}_{3}+\mathrm{N}_{2}+4 \mathrm{H}_{2} \mathrm{O} \quad \mathrm{E}=1.12 \mathrm{~V}
\end{gathered}
$$

The electrons released during the reaction are used in the decomposition of the palladium amine complex to palladium and ammonia gas with the deposition rate increasing with the number of available Palladium sites [15].

K. L. Yeung et al. (1999) (15) reported that the plating rate is dependant upon the concentration of palladium and the reducing agent. Yeung and his group [15] investigated the plating kinetics in electroless plating of thin supported Pd membranes and reported that the plating rate increased with increasing concentration of both the hydrazine reducer and palladium. However, excess concentration of the hydrazine reducer could lead to bulk precipitation of the Palladium metal [15] [22]. The plating rate reported by this group after I hour of plating and also the rate reported by Collins and Way (1993) [23] were between 1 and $3 \mu \mathrm{m} / \mathrm{hr}$ at $320-360 \mathrm{~K}$ with hydrazine and palladium precursor concen- 
tration of $10 \mathrm{~mL} / \mathrm{L}(1 \mathrm{M})$ and $3-5.5 \mathrm{~g} / \mathrm{L}$ respectively. Collins and Way (1993) [23] reported that the plating rate significantly reduced after 1 hour plating time as a result of bulk decomposition of hydrazine by palladium.

Hydrazine is known to decompose rapidly in the presence of palladium [15]. Yeung et al. [15] also reported that increasing the concentration of the hydrazine from 1.5 to $10 \mathrm{mM}$ increases the plating efficiency from 0.16 to 0.65 . They demonstrated that at different hydrazine concentrations of $1.5,3.3$ and $10 \mathrm{mM}, \mathrm{Pd}$ film thickness of $\sim 0.5, \sim 0.9$ and $\sim 1.75 \mu \mathrm{m}$ were achieved respectively. However, the plating efficiency began to decrease from 0.72 to 0.66 and 0.55 with the increase in the concentration of palladium from 5.1 to 10.2 to $20.2 \mathrm{mM}$ respectively [15]. This indicates that excessive concentration of palladium could result in low plating efficiency and low quality of deposits hence it is necessary to establish the optimum hydrazine concentration to achieve stability of the plating bath [15]. In a similar investigation carried out by Y. S. Cheng (1999) [24] on $\mathrm{Pd} / \mathrm{Ag}$ codeposition, high quality Palladium deposits were obtained at hydrazine concentration of up to $20 \mathrm{mM}$ and $\mathrm{Ag}$ content of 25 at\%.

B. K. R. Nair et al. (2007) [25] also reported an increase in the plating rate with increasing concentration of Palladium and hydrazine. The maximum plating rate reported by B. K. R. Nair is $1.4 \mu \mathrm{m} / \mathrm{h}$ which is in line with the findings of the Collins and Way group [23].

It has been reported that the concentration of hydrazine is the limiting factor in determining the plating rate and efficiency of the electroless plating method for palladium-based membranes [15]. Some investigations carried out [15] [23] have shown that bulk precipitation is likely to occur at concentrations above 10 $\mathrm{mM}$ as demonstrated by K. L. Yeung and coworkers (1999) [15].

Further investigations are necessary to provide a better understanding in terms of the effect of some of the operating conditions such as $\mathrm{pH}$ of plating bath, plating time and $\mathrm{NH}_{4} \mathrm{OH}$ on the effect of this bulk precipitation over a wide range of $\mathrm{N}_{2} \mathrm{H}_{4}$ concentrations [26]. To ameliorate the problem of bulk precipitation in hydrazine-based plating baths K. L. Yeung et al. (1999) [15] suggested adding hydrazine in two equal portions with the first portion added at the commencement of the plating while the second portion is added midway during the plating.

This group reported an increase of 0.13 in the plating efficiency when a solution containing $10.2 \mathrm{mM}(\mathrm{Pd})$ and $10 \mathrm{mM}\left(\mathrm{N}_{2} \mathrm{H}_{4}\right)$ is added in 2 equal portions as compared to the plating efficiency when all the solution was added at once [15]. Since this group of workers used 2 equal portions of the hydrazine solution, what is required now is further investigation by varying the portions of the hydrazine solution into 3 or more in order to establish a concentration profile of these portions that results in an improved or optimum plating efficiency. Also, Yeung et al. [15] didn't establish the effect of other variables such as plating temperature, time and concentration of EDTA and $\mathrm{NH}_{4} \mathrm{OH}$ when hydrazine is added in portions. Moreover there is the propensity that addition of separate 
portions of the hydrazine could lead to separate layers and uneven coating which could affect the quality of the palladium film.

\section{2. $\mathrm{pH}$ of the Plating Bath}

A constant $\mathrm{pH}$ of the plating solution should be maintained throughout the electroless plating process due to its effect on various phenomena that are associated with the metal-solution interface [26]. These phenomena include adsorption, structure of ions in the solution and the ionic strength of the gsolution which affects the plating rate and efficiency [17] [26]. The $\mathrm{pH}$ also affects the anodic and the $\mathrm{pH}$ on the anodic reaction where the reaction precedes charge transfer in the hypophosphite plating bath as represented in the following reactions [26]:

$$
\begin{gathered}
\mathrm{H}_{2} \mathrm{PO}_{2}^{-} \rightarrow \mathrm{HPO}_{2}^{-}+\mathrm{H} \\
\left(\mathrm{HPO}_{2}\right)^{-}+\mathrm{OH}^{-} \rightarrow\left(\mathrm{HPO}_{2} \mathrm{OH}\right)^{-}+1 \mathrm{e}^{-}
\end{gathered}
$$

It should be noted that a higher $\mathrm{pH}$ could lead to high plating rates and "plate-out" thus causing rough coating while a low $\mathrm{pH}$ could lead to low plating rates thus causing dull and uneven coating [15]. In another related investigation, F. Hanna et al. (2003) [21] reported an increase in the deposition rate of copper at $30^{\circ} \mathrm{C}$ and $50^{\circ} \mathrm{C}$ for the tartarate and EDTA baths up to $\mathrm{pH} 12.5$ for tartarate bath and 13.0 for the EDTA bath. Above these $\mathrm{pH}$ values, the rate of deposition of the Pd film decreases. F. Hanna et al. [21] attributed this decrease to the decomposition of the $\mathrm{OH}^{-}$ions through the hydrolysis of formaldehyde to methylene glycol and the subsequent formation of formate ions through the oxidation of methylene glycol. The reaction at $\mathrm{pH} 12$ and below can be represented as follows [21]:

$$
\mathrm{Cu}^{2+}+2 \mathrm{HCHO}+4 \mathrm{OH}^{-} \rightarrow \mathrm{Cu}^{0}+\mathrm{H}_{2}+2 \mathrm{H}_{2} \mathrm{O}+2 \mathrm{HCOO}^{-}
$$

While the reaction at $\mathrm{pH} 12.5$ and above can be represented as follows:

$$
\begin{gathered}
\mathrm{HCHO}+\mathrm{OH}^{-} \rightarrow \mathrm{CH}_{2}(\mathrm{OH}) \mathrm{O}^{-} \\
\mathrm{CH}(\mathrm{OH}) \mathrm{O}^{-}+\mathrm{OH}^{-} \rightarrow \mathrm{CHOO}^{-}+\mathrm{H}_{2} \mathrm{O}+\mathrm{e}^{-}
\end{gathered}
$$

Alkaline baths were reported to have higher deposition rate but decrease stability while acidic baths were observed to exhibit better adhesion characteristics particularly to stainless steel supports [1]. From the investigations conducted on the effect of $\mathrm{pH}$ of the plating bath on plating rate and efficiency, it can be construed that there is paucity of knowledge on the effect of $\mathrm{pH}$ of the plating bath in relation to other factors such as plating time and temperature. Most of the work on $\mathrm{pH}$ in electroless plating were carried out on the effect of $\mathrm{pH}$ on plating rate and not much was done on the effect of $\mathrm{pH}$ on the morphology of the deposits.

\subsection{Plating Bath Temperature}

The plating bath temperature should be maintained at desired levels using certi- 
fied thermometers in order to obtain consistent, uniform and high quality deposition [1]. The effect of bath temperature is related to the decomposition of the reducing agent in the plating bath and the plating efficiency increases with increase in the plating temperature [27]. However, at an optimum temperature, the plating efficiency starts to decrease due to the increase in the rate of decomposition of the reducing agent [15] [27]. The temperature range for optimum plating stability was reported by several authors [15] [21] to be in the range of $50^{\circ} \mathrm{C}-80^{\circ} \mathrm{C}$ but never to exceed $90^{\circ} \mathrm{C}$ to avoid bath decomposition or solution 'Plate out' [15]. However, the effect of temperature is also dependant on the stabilising agent in the bath since stabilising agents such as EDTA control the plating efficiency against temperature changes [15].

The stabilising agents ensure that temperature changes do not lead to excessive decomposition rates of the reducing agent up to the optimum temperature [15]. The control of these temperature changes depends on the type of stabilising agent and the composition of the plating bath [15] [26]. In this regard, Hanna and coworkers [21] used formaldehyde plating bath in the electroless plating of copper and reported an increase in the plating efficiency with increasing temperature.

This group used both EDTA and Tartarate plating baths. In the EDTA plating bath, the temperature was stable up to $70^{\circ} \mathrm{C}$ and the plating efficiency increased with temperature up to $70^{\circ} \mathrm{C}$, after which it begins to decrease. For the tartarate bath, above $50^{\circ} \mathrm{C}$, the plating efficiency begins to reduce due to the rapid decomposition of the tartarate complexing agent. This indicates that the EDTAbath has a stronger complexing ability compared to the tartarate-bath [21]. For electroless copper plating, the optimum temperatures were reported to be $50^{\circ} \mathrm{C}$ for the tartarate bath and $30^{\circ} \mathrm{C}$ for the EDTA bath [21]. Shin-Kun Ryi et al. (2010) [13] discovered that bulk precipitation occurred at $35^{\circ} \mathrm{C}$ thereby leading to instability of the plating solution which is as a result of the absence of the EDTA stabilising agent in the solution. The absence of the stabilising agent was the reason for the decomposition of the plating solution at a comparably lower temperature of $35^{\circ} \mathrm{C}$ which indicates that higher concentration of the stabilising agent could reduce the risk of bulk precipitation at high temperature [13].

The effect of plating bath temperature on the membrane morphology was also investigated by several authors including Shin-Kun Ryi et al. (2010) [13] who used electroless plating to deposit a $7.5 \mu \mathrm{m}$ palladium film onto porous hastlerooy in an EDTA free bath. Ryi's group [13] investigated the effect of plating bath temperature at $20^{\circ} \mathrm{C}, 30^{\circ} \mathrm{C}$ and $35^{\circ} \mathrm{C}$ on the surface morphology of the membrane and showed that grain size increases with temperature. Since larger grain sizes have better permeation then it follows that higher plating temperatures result in better membrane quality [13]. Ryi's group [13] showed that the bulk grains at $35^{\circ} \mathrm{C}$ were found to be smaller than the $20^{\circ} \mathrm{C}$ and $30^{\circ} \mathrm{C}$ baths but the surface grain size at $35^{\circ} \mathrm{C}$ was larger than those of the lower temperature. This is in concurrence with the findings of R. K. B Nair (2007) and his group [25] who synthesized palladium membranes on hollow fibres and reported a 
smaller grain sizes for lower plating bath temperatures. This group reported that a $23^{\circ} \mathrm{C}$ plating bath has a lower grain size $-0.5-1 \mu \mathrm{m}$-compared to a $50^{\circ} \mathrm{C}$ plating bath which has a grain size of $1-2 \mu \mathrm{m}$. This implies that a lower bath temperature leads to smaller grain sizes and since smaller grain sizes lead to better coating, then it follows that lower bath temperature will produce more hydrogen permeable membranes [25] [27]. The SEM images of the membranes after plating at 293, 303 and $308 \mathrm{~K}$ are shown in Figures 4(a)-(c) respectively and it can be from the images that the surface grain size became smaller and more uniform with decrease in the plating temperature while the bulk grains became smaller with increasing temperature [13].

\subsection{Air Exposure}

Air purges were initially used in surface cleaning during electroless plating of Pd and Pd alloy membranes but the method is increasingly becoming relevant in improving plating efficiency and quality of deposits [28].

Generally, the main contribution of air exposure has been reported to be in increasing the surface area and morphological changes to improve plating efficiency [21] [28]. A steady stream of air bubble through the plating solution has been reported to be the most common stabilizer for electroless copper plating baths [12]. In their work, Hanna and coworkers (2003) [21] investigated the effect of aeration on electroless plating bath with and without additives and reported an increase in the decomposition time to about 20 times than the baths without aeration which they attributed to the reoxidation of cuprous ion during the redox reaction at higher $\mathrm{pH}$ values by the formaldehyde reducer [21].

A similar finding was also reported by F. Roa and D. Way (2005) [28] who investigated

the effect of air exposure on $\mathrm{Pd} / \mathrm{Cu}$ composite membranes. Although the air aeration was performed after the plating of the membrane, nonetheless it provides a better understanding of the effect of air exposure in improving membrane quality. F. Roa and Way [28] reported that the air exposure at higher temperatures led to oxidation of the palladium film to produce PdO which created more surface area for enhanced film deposition. Most of the work done on the effect of air aeration is in palladium-copper membranes hence there is paucity of knowledge on the effect of air aeration at various temperatures in palladium and palladium-alloy. Further work on the effect of air aeration in electroless plating will be relevant in optimisation of the electroless plating process to improve the plating rate and efficiency.

\subsection{Plating Bath Temperature}

The plating rate and efficiency increases with plating time depending on the composition of the plating bath [15] [29]. K. L. Yeung et al. (1999) [15] reported that at certain point during the deposition process, the plating rate ceases to respond to film deposition which implies that no further deposition takes place. One reason for this could be that all the palladium in the solution has been de- 
posited [13]. M. Kitiwan and D. Atong (2010) [29] investigated the electroless plating of palladium on ceramic support and reported an increase in the rate of deposition with time. In their work, this group showed that the palladium deposition started after 10 minutes which indicates that there was an induction period before the commencement of the plating process. The 10 minutes induction period was high and rather unexplained because prior to the plating process, the ceramic support was activated with Pd nuclei which would have drastically reduced the induction period [15].

M. Volpe et al. (2006) [30] investigated the deposition of palladium on anodic alumina and reported stable plating below 30 minutes of deposition time. However, after 30 minutes there was damage to the membranes which was attributed to the plating time longer than 30 minutes and also the $\mathrm{pH}$ of the solution [30]. This group reported that after the stable $\mathrm{pH}$ of 8.4, the high alkalinity of the plating bath led to the unstable plating solution. Impliedly, if the $\mathrm{pH}$ has been higher than 8.4 and the plating time was less than 30 minutes, the plating rate would have been stable. This indicates that the effect of plating time on the quality of deposits also depends on the $\mathrm{pH}$ of the plating solution [15] [30]. The effect of plating time is also dependant on the concentration of the metal and the reducing agent as shown by K. L. Yeung et al. (1999) [15] who reported an increase in the plating efficiency with time for 2 different reducing agents: Hydrazine and hypophosphite reducers for plating periods of 1 and 4 hours. Palladium was shown to deposit continuously over the 4 hour plating time in the hypophosphite bath with increase in the plating efficiency but the plating efficiency decreases from 0.96 to 0.79 as the concentration of palladium increases from 2.8 to $11.3 \mathrm{mM}$. However, the plating efficiency decreased with increase in the palladium concentration for both the hydrazine and hypophosphite baths but the plating rate and the final amount deposited increased [15]. There is the need for a better understanding of the effect of plating time vis-à-vis the concentration of the reducer and stabilising agent. Furthermore, there is paucity of knowledge as to whether or not the plating time will enhance plating efficiency at low or high temperatures.

The effect of plating time on the deposits morphology has been reported by several authors including Y. S. Cheng et al. (1999) [24]. In their work on PdAg codeposition on Vycor glass support, this group reported that at the beginning of the plating i.e. $\mathrm{t}=0$, there was generally a uniform seeding of the support but after 10 minutes, there was a mixed coating of silver and a nonuniform coating begins to appear. At 20 minutes, there was a more rapid growth of some of the grains compared to the others and the film assumed a nonuniform grain size and between 20,30 and 40 minutes plating time, there was simultaneous nucleation and growth but a dense film was achieved at the end of 60 minutes [24]. Also, this group of workers reported that as the plating time increases, so does the competition for nucleation sites but if the initial deposition rate of silver is high, then palladium could be prevented from deposition which could result in a pure silver membrane [15]. 
To ameliorate this problem, a higher concentration of hydrazine reducing agent is added [15]. Competition for nucleation sites between silver and palladium leads to inhibition of palladium deposition if the initial rate of deposition of silver is high and this result in uneven coating which could also be improved by the addition of a higher concentration of the hydrazine reducing agent to enhance palladium deposition [24].

Also in an effort to solve this problem, Gaofeng Zeng et al. (2014) [31] developed a method which adjusted the imbalance in the deposition rate of the metals and regulated the competition for nucleation sites between both metals. The Gaofeng group developed a silver controlled codeposition method for the preparation of PdAg membranes in separate Pd and Ag plating baths. Silver is continuously fed into the palladium plating bath to restrict the silver concentration. Although this method showed some nonuniform distribution of the metal, it still improved the stability of the plating bath by reducing the precipitation of the plating bath. In this method, thin $\mathrm{Pd} / \mathrm{Ag}$ membranes of $\sim 2.5 \mu \mathrm{m}$ and uniform silver distribution of $\sim 25 \%$ were achieved [31].

\subsection{Stabilising Agent}

The plating solution for electroless plating usually contains EDTA (ethyldiamine triacetate) which serves as a complexing agent and stabilises the plating bath by controlling the plating process against temperature changes [15]. However, EDTA also has its drawbacks as it affects the purity of the palladium layer due to the absorption of the EDTA complex in the metal deposits [13]. F. Braun et al. (2011) [32] in their work discovered that membranes prepared without EDTA showed cracks and a dendritic morphology but the morphology of membranes prepared with EDTA and low concentration of hydrazine were more homogeneous. The effect of EDTA at different concentrations of the reducer has not been fully investigated to provide a better understanding as to the optimum EDTA concentration (wt \%) at which the impurities could be avoided to achieve full bath stability. The concentration of the $\mathrm{NH}_{4} \mathrm{OH}$ stabilizing agent is another factor that affects the plating rate. Yeung et al. (1999) [15] investigated the effect of $\mathrm{NH}_{4} \mathrm{OH}$ by using different concentrations of the stabilizing agent and reported that high concentrations of $\mathrm{NH}_{4} \mathrm{OH}$ above $7 \mathrm{M}$ led to a decrease in the plating rate. However, at low concentration of $\mathrm{NH}_{4} \mathrm{OH}$, the plating rate increased but this increase was succeeded by decomposition of the plating bath [15]. Several investigations have shown that the plating efficiency increases with decreasing concentration of the $\mathrm{NH}_{4} \mathrm{OH}$ [13] [15]. K. L. Yeung et al. (1999) [15] reported an increase in the amount of palladium deposited with decreasing concentration of $\mathrm{NH}_{4} \mathrm{OH}$.

\subsection{Additives}

In addition to the complexing agents such as EDTA and Potassium/Sodium tartarate, additives also stabilize the bath against the spontaneous decomposition of plating baths and the formation of unwanted particles which could inhibit the 
plating efficiency [21]. Some of the additives used in electroless plating are 2,2bipyridyl, mercaptobenzothiazole, thiourea and cyanide and they have been used as stabilizers in electroless plating to enhance plating rate and efficiency [21]. F. Hanna et al. (2003) [21] investigated the effect of several additives namely Cytosine, Thiourea, 2- mercaptobenzothiazole (2MBT), benzotriazole (BT) and Pyridine in the electroless plating of copper on pure copper coupons using formaldehyde as the reducing agent and reported a marked increase in the plating rate upon the addition of additives. The group reported an increase in the plating rate from 5.4 to $10.5 \mathrm{mg} / \mathrm{cm}^{2} \mathrm{~h}$ when $2 \mathrm{mg} / \mathrm{l}$ of $2 \mathrm{MBT}$ is added to the EDTA bath at $\mathrm{pH} 13$.

These additives have a greater adsorption ability at low concentrations on active copper sites compared to the EDTA hence the increase in the plating rate [13] [21]. But the phenomenon is only at low concentrations because at concentrations above $2 \mathrm{mg} / \mathrm{l}$ of $2 \mathrm{MBT}$, the plating rate begins to reduce steadily [21]. All the organic compounds investigated by this group exhibited similar trend which was also reported by Yang, Z et al. (2011) [33] in their investigation on the addition of Polyethylene glycol (PEG), Polypropylene glycol (PPG) and ethylene oxide terminal blocks termed EPE. Pizzi, et al. (2008) [34] also discovered that the plating rate decreases with an increase in the concentration of the additive up to $2 \mathrm{mg} / \mathrm{l}$. Pizzi and his group [34] used $\mathrm{SiO}_{2} / \mathrm{Si}$ substrate for the electroless copper plating using a formaldehyde reducer and EDTA complexing agent at an optimum plating bath temperature of $70^{\circ} \mathrm{C}$, plating time of $60 \mathrm{~min}$ utes and a $\mathrm{pH}$ of 12.5. The Pizzi group also reported that at lower concentration of $0.5 \mathrm{mg} / \mathrm{l}$ and below, the difference in the plating rate was not profound but it increased with additional concentration of the stabilizers up to $2 \mathrm{mg} / \mathrm{l}$ when the plating rate starts to decrease. It is noteworthy that most of the work done on additives is on the electroless plating of copper hence there is paucity of knowledge regarding the effect of additives on the electroless plating of palladium and its alloys.

\subsection{Deposits Morphology}

Palladium membranes suffer from hydrogen embrittlement and $\mathrm{Pd} / \mathrm{Ag}$ membranes are resistant to hydrogen embrittlement due to their ability to avoid $\alpha-\beta$ phase transition [3]. It is necessary to investigate the morphology of the deposits in electroless plating of palladium and palladium alloy membranes so as to provide a better understanding of the process and how the electroless plating factors could be optimised to improve hydrogen permeation. A better understanding of the effect of the process factors on deposits morphology will also provide a better understanding of the quality of these deposits and by implication, the plating rate and efficiency which also affects the hydrogen permeation properties [15]. Process factors such as plating rate, time, temperature and reducing agent determine the growth of the palladium film and grain size [27].

It has been reported that smaller grains generally lead to better coating and denser films as a result of the larger boundaries associated with the larger grains 
which could impede the selectivity of the membrane [10]. Even smaller grains may have larger boundary gap which implies that both smaller and larger grain sizes could affect the selectivity of the membrane [10] [27].

From the several investigations conducted it is apparent that there is paucity of knowledge on the effect of grain sizes on quality of deposits hence further studies are required to ascertain the effect of grain size on the quality of the palladium films. Investigations have shown that lower temperatures and lower plating cycles result in smaller grain growth and better uniformity of coating [10]. Also low temperatures maintain a uniform grain growth for much longer periods than high temperatures [10] [27]. Lower plating cycles result in more uniformly coated membranes and reduce the risk of defects in the metallic layer [27].

M. L. Bosko et al. (2011) [10] investigated the effect of plating time on the morphology of Pd-Ag films deposited over porous stainless steel support using the electroless plating method using 2 separate plating periods i.e. 90 minutes and 40 minutes over a plating cycle of 3 and 9 rounds respectively. This group [10] reported that a higher number of plating cycles resulted in more defects in the metallic film and increased the detrimental effect of silver dendrites growth which Huey-Ing [35] and his group attributed to the different growth patterns of the Pd and Ag grains. Y. S. cheng et al. [24] investigated the preparation of $\mathrm{Pd} / \mathrm{Ag}$ membranes on porous Vycor tube and reported that higher concentration of hydrazine promotes the deposition of palladium. Furthermore, they also posited that at higher hydrazine concentration-20 $\mathrm{mM}-$ pure palladium films were obtained even though the silver concentration was higher at 25 at $\%$. However, increasing the amount of $\mathrm{NH}_{4} \mathrm{OH}$ can improve the deposition of $\mathrm{Pd}$ and enhance that of Ag but very low concentration of $\mathrm{NH}_{4} \mathrm{OH}$ can result in bulk precipitation [24]. From their findings, this group of workers [24] concluded that the optimum plating bath conditions for a $\mathrm{Pd} / \mathrm{Ag}$ codeposition are: 1) A low concentration of $\mathrm{NH}_{4} \mathrm{OH}$. 2) A modest hydrazine to palladium ratio and 3) A high plating temperature.

In $\mathrm{Pd} / \mathrm{Ag}$ electroless codeposition, the effect of Ag content in the plating bath on the deposits morphology has been studied by several authors [28] Huey-Ing Chen and his group (2004) [35] reported that the plating bath for pure palladium without silver showed nodular palladium agglomerates but when the silver content was added up to $50 \%$, the layer became dendritic with crystallites whose porosity reaches a maximum at $50 \% \mathrm{Ag}$ content. The group demonstrated that the $\mathrm{Ag}$ content in the deposited film increased as the $\mathrm{Ag}$ content in the plating bath increased [35]. It was observed that there was more Ag in the deposited layer than in the plating bath which indicates that under the plating conditions Ag inhibits the deposition of palladium [27] [35]. Also, there was no Ag for the 2 and 3 hour plating times except at $10 \% \mathrm{Ag}$ content which implies that the strength of inhibition of palladium deposition by Ag decreased as the Ag content in the plating bath is reduced [35].

The deposit morphology of the $\mathrm{Pd} / \mathrm{Ag}$ membranes was also investigated by 
Huey-Ing Chen et al. [35] and after varying the silver content of the plating bath at $50 \%, 25 \%, 12.5 \%$, and 6.2 at\%, they reported Ag content (at\%) of 100, 30, 12.5 and 5.5 respectively. Y. S Cheng et al. [24] also compared the microstructure of the pure palladium and codeposited $\mathrm{Pd} / \mathrm{Ag}$ films from the same plating bath conditions and reported that silver is dominant and it inhibits palladium deposition if its initial plating rate is high and could even lead to a pure silver membrane. However, the inhibition of deposition by either silver or palladium over the other metal depends on the initial plating rate. A high initial rate of palladium could result in inhibition of $\mathrm{Ag}$ deposition and same also for a high initial rate of silver. It is necessary that the initial plating rates for palladium and silver are controlled so as to avoid the inhibition of deposition for any of the metals [24].

Y. S. Cheng and K. L. Yeung [24] prepared a Pd/Ag membrane with thickness from a plating bath containing $10 \mathrm{mM} \mathrm{Pd} / \mathrm{Ag}$ solution, Hydrazine concentration at $10 \mathrm{mM}$ and temperature $328 \mathrm{~K}$ and reported that the plating bath with high concentrations formed a continuous film with small and uniform grain sizes while that with lower silver concentrations showed a flowery structure and larger grain size. The uneven grain sizes can be attributed to the inhibition effect of silver in the plating bath. At higher initial concentration of silver, there was a "domino" effect exerted by silver which inhibits palladium deposition [24]. Cheng and his group reported a better performance in hydrogen permeation for the $\mathrm{Pd} / \mathrm{Ag}$ membranes compared to the Pure Pd membrane. There is very little work on the effect of $\mathrm{pH}$ and other process factors on the morphology of palladium membranes prepared through the electroless plating method.

\section{Conclusions}

In this review, the effect of process factors such as plating temperature, time, $\mathrm{pH}$, reducing agent, additives and air aeration on plating rate and efficiency including pre-plating procedures of sensitization and activation were investigated. Also, the effect of some of these factors on morphology of deposits in $\mathrm{Pd} / \mathrm{Ag}$ electroless plating was investigated. The sensitization and activation steps not only improved the plating efficiency but also make the plating process prone to contamination from Tin impurities which lead to lower plating rate and uneven coating. Increasing the concentration of hydrazine reducer will increase the plating rate but excess hydrazine leads to bulk precipitation. Hence other reducing agents such as hypophosphite and formaldehyde (for copper plating) are also considered. The $\mathrm{pH}$ of the plating solution also increases the plating efficiency but higher $\mathrm{pH}$ could lead to 'plate out' and uneven coating. Lower $\mathrm{pH}$ was found to enhance adhesion of the film to the substrate and also lead to homogeneous microstructure. The optimum temperature for plating bath stability was found to be in the range $50^{\circ} \mathrm{C}-70^{\circ} \mathrm{C}$.

Furthermore, several gaps in knowledge were identified which need further investigation including how best to avoid the problem of bath decomposition 
which occurs as a result of excess concentration of the reducer. The concentration of the reducer is the limiting factor in determining plating rate and efficiency and increase in its concentration enhances the plating rate and efficiency but at a particular concentration, bath decomposition occurs which 'stagnates' metal decomposition. The challenge is how to determine the optimum value of other process factors such as plating temperature, time, and $\mathrm{pH}$ such that the concentration of the reducer could be increased without necessarily causing bath decomposition.

\section{Acknowledgements}

Sincere thanks to Petroleum Technology Development Fund (PTDF) Nigeria for funding this work.

\section{Conflicts of Interest}

The author declares no conflicts of interest regarding the publication of this paper.

\section{References}

[1] Schlesinger, M. and Paunovic, M. (2010) Modern Electroless Plating. Chapter 18, Wiley and sons, Inc., New York, 447-458. https://doi.org/10.1002/9780470602638.ch18

[2] Yun, S. and Oyama, T.S. (2011) Correlations in Palladium Membranes for Hydrogen Separation: A Review. Journal of Membrane Science, 375, 28-48. https://doi.org/10.1016/j.memsci.2011.03.057

[3] Gobina, E. and Hughes, R. (1996) Reaction Assisted Hydrogen Transport during Catalytic Dehydrogenation in a Membrane Reactor. Applied Catalysis, 137, 119-127. https://doi.org/10.1016/0926-860X(95)00312-6

[4] Dittmeyer, R., Hollein, V. and Daub, K. (2001) Membrane Reactors for Hydrogenation and Dehydrogenation Processes Based on Supported Palladium. Journal of Molecular Catalysis, 173, 135-184. https://doi.org/10.1016/S1381-1169(01)00149-2

[5] Wang, L., Yoshiie, R. and Uemiya, S. (2007) Fabrication of Novel Pd-Ag- $\mathrm{Ru} / \mathrm{Al}_{2} \mathrm{O}_{3}$ Ternary Alloy Composite Membrane with Remarkably Enhanced Hydrogen Permeability. Journal of Membrane Science, 306, 1-7. https://doi.org/10.1016/j.memsci.2007.08.057

[6] Balat, M. (2008) Potential Importance of Hydrogen as a Future Solution to Environmental and Transportation Problems. International Journal of Hydrogen Energy, 33, 4013-4029. https://doi.org/10.1016/j.ijhydene.2008.05.047

[7] Li, A., Xiong, G., Gu, J. and Zheng, L. (1996) Preparation of Pd/Ceramic Composite Membrane 1. Improvement of the Conventional Preparation Technique. Journal of Membrane Science, 110, 257-260. https://doi.org/10.1016/0376-7388(95)00249-9

[8] Chee, C. and Gobina, E. (2010) Ultra-Thin Palladium Technologies Enable Future Commercial Deployment of PEM Fuel Cell Systems. Membrane Technology, 2010, 6-13. https://doi.org/10.1016/S0958-2118(10)70054-9

[9] David, E. and Kopac, J. (2010) Development of Palladium/Ceramic Membranes for Hydrogen Separation. International Journal of Hydrogen Energy, 36, 4498-4506. https://doi.org/10.1016/j.ijhydene.2010.12.032 
[10] Basko, M.L., Lombardo, E.A. and Cornaglia, L.M. (2011) The Effect of Electroless Plating Time on the Morphology, Alloy Formation and $\mathrm{H}_{2}$ Transport Properties of Pd-Ag Composite Membranes. International Journal of Hydrogen Energy, 36, 4068-4078. https://doi.org/10.1016/j.ijhydene.2010.12.056

[11] Bulasara, K.V., Thakuria, H., Uppaluri, R. and Purkait, K.M (2011) Effect of Process Parameters on Electroless Plating and Nickel-Ceramic Membrane Characteristics. Desalination, 268, 195-203. https://doi.org/10.1016/j.desal.2010.10.025

[12] Pandey, P. and Chauhan, R.S. (2001) Membranes for Gas Separation. Progress in Polymer Science, 26, 853-893. https://doi.org/10.1016/S0079-6700(01)00009-0

[13] Ryi, S.-K., Xu, N., Li, A., Lim, J.C. and Grace, J.R. (2010) Electroless Pd Membrane Deposition on Alumina Modified Porous Hastleloy Substrate with EDTA-Free Bath. International Journal of Hydrogen Energy, 35, 2328-2335. https://doi.org/10.1016/j.ijhydene.2010.01.054

[14] Balamurali, K.R.N., Choi, J. and Harold, P.M. (2007) Electroless Plating and Permeation Features of Pd and Pd/Ag Hollow Fiber Composite Membranes. Journal of Membrane Science, 288, 67-84. https://doi.org/10.1016/j.memsci.2006.11.006

[15] Yeung, K.L., Christianiansen, S. and Varma, A. (1999) Palladium Composite Membranes by Electroless Plating Technique: Relationship between Plating Kinetics, Film Microstructure and Membrane Performance. Journal of Membrane Science, 159, 107-122. https://doi.org/10.1016/S0376-7388(99)00041-1

[16] Cheng, Y.S., Pena, M.A., Fierro, J.L., Hui, D.C.W. and Yeung, K.L. (2002) Performance of Alumina, Zeolite, Palladium, Pd-Ag Alloy Membranes for Hydrogen Separation from Towngas Mixture. Journal of Membrane Science, 204, 329-340. https://doi.org/10.1016/S0376-7388(02)00059-5

[17] Khoperia, T.N. (2003) Investigation of the Substrate Activation Mechanism and Electroless Ni-P Coating Ductility and Adhesion. Microelectronic Engineering, 69, 391-398. https://doi.org/10.1016/S0167-9317(03)00326-5

[18] Zhao, H.-B., Pflanz, K., Gu, J.-H., Li, A.-W., Stroh, N., Brunner, H. and Xiong, G.-X. (1998) Preparation of Palladium Composite Membranes by Modified Electroless Plating Procedure. Journal of Membrane Science, 142, 147-157. https://doi.org/10.1016/S0376-7388(97)00287-1

[19] Zhang, X., Xiong, G. and Yang, W. (2008) A Modified Electroless Plating Technique for Thin Dense Palladium Composite Membranes with Enhanced Stability. Journal of Membrane Science, 314, 226-237. https://doi.org/10.1016/j.memsci.2008.01.051

[20] Xu, L.N., Liao, J.H., Huang, L., Ou, D.L., Zhou, K.C., Zhang, H.Q., Gu, N. and Liu, J.Z. (2002) A New Activation Method for Electroless Metal Plating: Palladium Laden via Bonding with Self-Assembly Monolayers. Chinese Chemical Letters, 13, 687-688.

[21] Hannah, F., Abdel Hamid, Z. and Abdel Aal, A. (2003) Controlling Factors Affecting the Stability and Rate of Electroless Copper Plating. Materials Letters, 58, 104-109. https://doi.org/10.1016/S0167-577X(03)00424-5

[22] Okinaki, Y. and Kato, M. (2010) Electroless Deposition of Gold. In: Modern Electroless Plating, Fifth Edition, Chapter 21, John Wiley and Sons, New York, 483-498. https://doi.org/10.1002/9780470602638.ch21

[23] Collins, J.P. and Way, D. (1993) Preparation and Characterisation of a Composite Palladium-Ceramic Membrane. Industrial \& Engineering Chemistry Research, 32, 3006-3013. https://doi.org/10.1021/ie00024a008

[24] Cheng, Y.S. and Yeung, K.L. (1999) Palladium-Silver Composite Membranes for Electroless Plating Technique. Journal of Membrane Science, 158, 127-141. 
https://doi.org/10.1016/S0376-7388(99)00009-5

[25] Nair, R.K.B., Choi, J. and Harold, P.M. (2007) Electroless Plating and Permeation Features of $\mathrm{Pd}$ and $\mathrm{Pd} / \mathrm{Ag}$ Hollow Fibre Composite Membranes. Journal of Membrane Science, 288, 67-84. https://doi.org/10.1016/j.memsci.2006.11.006

[26] Anik, T., Touhami, E.M., Himm, K., Schireen, S., Belkhmima, R.A, Abouchane, M. and Cisse, M. (2012) Influence of pH Solution on Electroless Copper Plating Using Sodium Hypophosphite as Reducing Agent. International Journal of Electrochemical Science, 7, 2009-2018.

[27] Ayturk, M.E. and Ma, Y.H. (2009) Electroless Pd and Ag Deposition Kinetics of the Composite $\mathrm{Pd}$ and $\mathrm{Pd} / \mathrm{Ag}$ Membranes Synthesised from Agitated Plating Baths. Journal of Membrane Science, 330, 233-245.

https://doi.org/10.1016/j.memsci.2008.12.062

[28] Roa, F. and Way, J.D. (2005) The Effect of Air Exposure on Palladium-Copper Composite Membranes. Applied Surface Science, 240, 85-104. https://doi.org/10.1016/j.apsusc.2004.06.023

[29] Kitiwan, M. and Atong, D. (2009) Effects of Porous Alumina Support and Plating Time on Electroless Plating of Palladium Membranes. Journal of Material Science Technology, 26, 1148-1152. https://doi.org/10.1016/S1005-0302(11)60016-9

[30] Volpe, M., Inguanta, R., Piazza, S. and Sunseri, C. (2006) Optimized Bath for Electroless Deposition of Palladium on Amorphous Alumina Membranes. Surface and Coatings Technology, 200, 5800-5806. https://doi.org/10.1016/j.surfcoat.2005.08.126

[31] Zeng, G., Shi, L., Liu, Y., Zhang, Y. and Sun, Y. (2014) A Simple Approach to Uniform Pd/Ag Alloy Membranes: Comparative Study of Conventional and Silver Concentration-Controlled Co-Plating. International Journal of Hydrogen Energy, 39, 4427-4436.

[32] Braun, F., Tarditi, M.A. and Cornaglia, L.M. (2011) Optimisation and Characterisation of Electroless Codeposited PdRu Membranes: Effect of the Plating Variables on Morphology. Journal of Membrane Science, 382, 252-261.

https://doi.org/10.1016/j.memsci.2011.08.019

[33] Yang, Z., Wang, Z., Wang, X. and Wang, Z. (2011) Comparison of Bottom-up Filling in Electroless Plating with an Addition of PEG, PPG and EPE. Chinese Journal of Chemistry, 29, 422-426. https://doi.org/10.1002/cjoc.201190098

[34] Pizzi, D., Worth, R., Baschetti, M.G., Sarti, G.C. and Noda, K. (2008) Hydrogen Permeability of 2.5 um Palladium-Silver Membranes Deposited on Ceramic Supports. Journal of Membrane Science, 325, 446-453.

https://doi.org/10.1016/j.memsci.2008.08.020

[35] Chen, H.-I., Chu, C.-Y. and Huang, T.-C. (2004) Characterization of $\mathrm{PdAg} / \mathrm{Al}_{2} \mathrm{O}_{3}$ Composite Membrane by Electroless Codeposition. Thin Solid Films, 460, 62-71. https://doi.org/10.1016/j.tsf.2004.01.106 